\title{
Advancing Discovery of Snail Mucins Function and Application
}

\author{
Maxwell McDermott ${ }^{1}$, Antonio R. Cerullo ${ }^{1}$, James Parziale ${ }^{1}$, Eleonora Achrak ${ }^{1}$, \\ Sharmin Sultana ${ }^{1}$, Jennifer Ferd ${ }^{1}$, Safiyah Samad ${ }^{1}$, William Deng ${ }^{1}$, \\ Adam B. Braunschweig ${ }^{1,2,3}$ and Mandë Holford ${ }^{1,3,4,5 *}$
}

${ }^{1}$ Department of Chemistry and Biochemistry, Hunter College, New York, NY, United States, ${ }^{2}$ Advanced Science Research Center, Graduate Center of New York, Graduate Department of Biochemistry, New York, NY, United States, ${ }^{3}$ PhD Programs in Biochemistry and Chemistry Graduate Center of the City University of New York, New York, NY, United States, ${ }^{4}$ PhD Program in Biology Graduate Center of the City University of New York, New York, NY, United States, ${ }^{5}$ Department of Invertebrate Zoology, The American Museum of Natural History, New York, NY, United States

OPEN ACCESS

Edited by:

Renjith P. Johnson,

Yenepoya University, India

Reviewed by:

Spyridon Ntougias,

Democritus University of Thrace,

Greece

Ashley Carson Brown North Carolina State University,

United States

*Correspondence:

Mandë Holford

mholford@hunter.cuny.edu

Specialty section:

This article was submitted to Biomaterials,

a section of the journal

Frontiers in Bioengineering and Biotechnology

Received: 30 June 2021 Accepted: 06 September 2021

Published: 11 October 2021

Citation:

McDermott M, Cerullo AR, Parziale J, Achrak E, Sultana S, Ferd J, Samad S,

Deng W, Braunschweig $A B$ and

Holford M (2021) Advancing Discovery

of Snail Mucins Function

and Application.

Front. Bioeng. Biotechnol. 9:734023.

doi: 10.3389/fbioe.2021.734023
Mucins are a highly glycosylated protein family that are secreted by animals for adhesion, hydration, lubrication, and other functions. Despite their ubiquity, animal mucins are largely uncharacterized. Snails produce mucin proteins in their mucous for a wide array of biological functions, including microbial protection, adhesion and lubrication. Recently, snail mucins have also become a lucrative source of innovation with wide ranging applications across chemistry, biology, biotechnology, and biomedicine. Specifically, snail mucuses have been applied as skin care products, wound healing agents, surgical glues, and to combat gastric ulcers. Recent advances in integrated omics (genomic, transcriptomic, proteomic, glycomic) technologies have improved the characterization of gastropod mucins, increasing the generation of novel biomaterials. This perspective describes the current research on secreted snail mucus, highlighting the potential of this biopolymer, and also outlines a research strategy to fulfill the unmet need of examining the hierarchical structures that lead to the enormous biological and chemical diversity of snail mucus genes.

Keywords: mucins, mucus, snails, biopolymer, biotechnology, cosmetics

\section{INTRODUCTION}

Intrigue in the mucus slime trails left by snails and slugs date back to ancient Greece, where they utilized the mucus for its ability to reduce inflammation and the signs of aging (Ekin, 2018). Today snail mucus is still used in skin care products by various companies and is a growing market whose value is expected to approach $\$ 770$ million by 2025 (Coherent Market Inisghts, 2018). Despite its commercial applications, the field of mucus research remains surprisingly underdeveloped. The primary constituent that is responsible for the properties of mucus are secreted mucins, a family of heavily glycosylated proteins produced in epithelial cells in most animals. Mucins are either bound to the plasma membrane or secreted out of the cell, and each type has major differences in their functions and capabilities (Dhanisha et al., 2018). Membrane-bound mucins are glycolipids that act as markers for cell signaling and also protect the cell from extracellular affronts that might lead to damage, such as infections and physical strain (Van Putten and Strijbis, 2017). Secreted mucins can be either gel forming or non-gel forming biopolymers. Secreted biopolymers form mucous membranes macroscopic scale. These mucosal membranes account for a large portion of the surface area of multicellular organisms exposed to the environment. In humans, mucosal membranes 


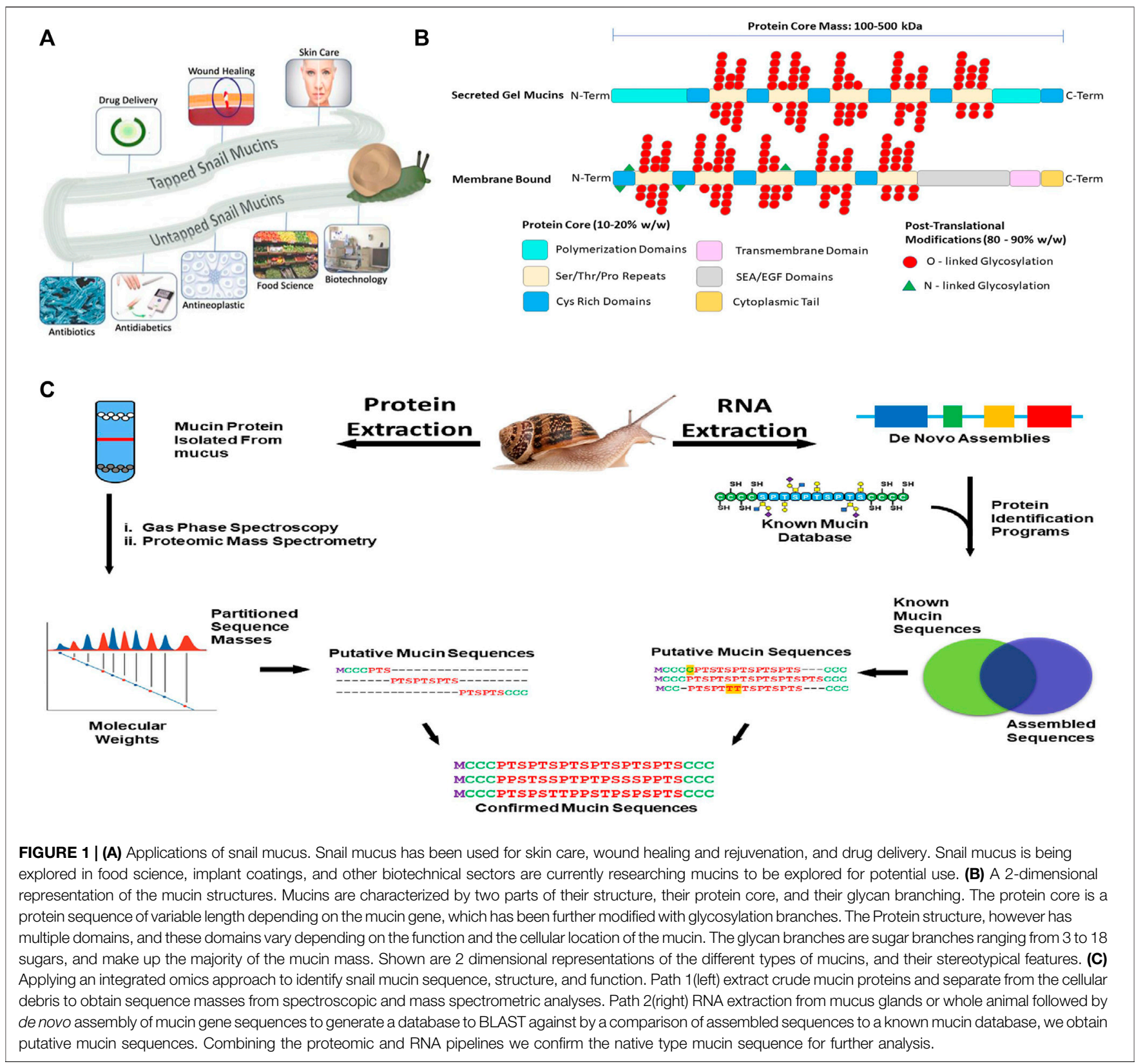

account for $99 \%$ of the bodies surface area (Sompayrac, 2012; Ma et al., 2018; Cerullo, 2020). Each snail species secretes multiple distinct functional mucuses. The mucus produced by a snail's foot is used for adhesion and for lubrication, allowing the snail to stick onto or walk across any surface, even while inverted. Additionally, the mucus produced on the back of the snail is used for microbial defense and tissue hydration. Certain snail species have specialized uses for mucus. For example, Falsilunatia eltanini (Moon Snail) uses mucus to protect their eggs, and Tikoconus costarricanus (Costa Rican Land Snail), uses mucus for load-bearing activities, such as to hide from the Sun on the bottom of leaves during droughts (Gould et al., 2019; Barrientos, 2020). Recent advances in omics (genomic, transcriptomic, proteomic, glycomics) technologies have expanded the exploration of gastropod mucins as a scientific resource with wide ranging applications across chemistry, biology, biotechnology, and medicine. For example, the antimicrobial properties of snail mucus are being used to combat disorders seen in humans ranging from gastric ulcers, to post-surgicalrelated infections (Amah et al., 2019; Gentili et al., 2020). Mucins are also being coupled with approved therapeutics in order to potentiate the drug's abilities to cure diseases, such as diabetes and ulcerative colitis (Gugu et al., 2020). Additionally, snail mucins are being investigated in a vast array of other biotechnical applications that exploit their surfactant-like properties (Petrou and Crouzier, 2018). Despite their potential, little is known about how the hierarchical mucin structures account for their diverse functional properties. There is an 
unmet need to examine the biological and chemical diversity of snail mucin genes to elucidate the guiding principles that determine the diverse properties associated with each gene. This perspective article will highlight current applications of secreted snail mucus that demonstrate the potential of this biopolymer as a resource for biotechnological and biomedical advancements. We will also describe an integrated omics strategy for investigating the biological and chemical diversity of snail mucus genes (Figure 1).

\section{Structural Variations of Mucins}

Mucins contain several domains that contribute to their overall function (Figure 1). The structural variation allows for their extensive biological diversity and unique physical characteristics. A tandem repeat domain located in the center of the protein backbone, rich in serine, threonine, and proline, serves an as anchor for glycosylation. Mucin glycans are predominantly O-linked, but minor amounts of $\mathrm{N}$-linked glycans can be present (Corfield, 2015). The length of the glycosylation domain and number of repeats differs between mucins and imparts different chemical characteristics. Secreted mucins have cysteine-rich regions on both ends of the tandem repeat domain that are used for stabilization, providing disulfide bridge points for both inter- and intramolecular bonding. Additionally, these regions serve both to provide additional structural diversification, and allow for multimerization of mucins and other sulfur-rich biomolecules (Perez-Vilar and Hill, 1999).

Typically, N-acetylgalactosamine (GalNAc) is attached to the protein core via $\mathrm{O}$-glycosidic bonds between the monosaccharide and either Ser or Thr residues (GalNAc[a1]-Ser/Thr). This forms the TN Antigen, which is commonly found in humans to be upregulated in certain cancers (Guillen-Poza et al., 2020). From there, galactose is appended to the structure (Gal[ $\beta 1-3] \mathrm{GalNAc}$ [a1]-Ser/Thr), forming the mucin core $1 \mathrm{O}$-glycan. O-glycans vary in size, from 2 to 20 sugar residues, and in composition, as other sugars such as $\mathrm{N}$-acetylglucosamine (GlcNAc) and fucose (Fuc) are appended sequentially (Brockhausen, 1999). Sialic acids and mannose are also found in trace amounts. Sialic acids in particular, have been to known to play a major role in the immune properties of mucins. Sialic acid mediates cell-to-cell interactions, along with being able to mask antigens from human macrophages (Yan et al., 2020). Further, sialic acids are the major binding points for lectins, a common protein family found in the innate immune system (Bornhöfft et al., 2018). Additionally, secreted mucins also exhibit C-mannosylation, where $\mathrm{C} 1$ of mannose bonds with the indole ring in tryptophan, allowing for greater variation of tertiary structure (Linden et al., 2008).

Subtle changes within the mucin structure, in particular the amino acid sequence and glycosylation, can correspond to vastly different biological function (Bansil and Turner, 2006). While these proteins are predominantly carbohydrates by weight, up to $90 \%$, both protein and glycan structures provide overall functional characteristics to the mucin (Linden et al., 2008). Additionally, individual mucins can have multiple glycoforms in normal and diseased states, and different populations of a single species can exhibit distinct glycoforms (Benktander et al., 2019). This diversity allows for organisms to individualize each mucin for specific physiological and environmental conditions. Overall there is little known about the genotype-to-phenotype connection of mucin genes that leads to the various functional properties. Several human mucin genes have been identified and there are at least 21 validated mucin coding genes, each with different biological activities (Rose and Voynow, 2006). In contrast, while many putative snail mucin genes have been identified none been validated. However, the lack of robust characterization of the genetics and structural differences between snail mucuses has not precluded their application to address pressing medical and biotechnological materials needs.

\section{Snail Mucins as Antimicrobial Agents}

Antibiotic-resistant bacteria are becoming an increasingly prevalent issue without many viable solutions. Because mollusks lack adaptive immunity, they depend on physical barriers and innate immunity for protection against pathogenic agents (Gerdol, 2017). For most snails, the foot has the most contact with surfaces that are contaminated with pathogens and parasites, and secretion of mucus along the feet protects against such microbes. One of the earliest mucuses evaluated for antimicrobial activity was that of Achatina fulica (Giant African Land Snail) (Table 1) (Iguchi et al., 1982). Mucus from A. fulica (Mumuni et al., 2020) demonstrated promising antibacterial activity against the Gram-positive bacteria, Bacillus subtilis and Staphylococcus aureus, and the Gram-negative bacteria, Escherichia coli and Pseudomonas aeruginosa (Table 2). The mucus secretions of A. fulica inhibited the bacterial growth of both $S$. aureus and $S$. epidermidis when applied via wound dressing films on a mouse model (Santana et al., 2012). The wound dressings improved the maturation of granulation tissue and the rate of collagen deposition, which are known to expedite the healing process (Martins et al., 2003). In a similar study, the mucus of Helix aspersa demonstrated antimicrobial activity against several strains of Pseudomonas aeruginosa (Pitt et al., 2015). Further, the mucus of both $A$. marginata and $A$. fulica, were utilized as wound dressinsg on 28 clinical wound samples collected with known common infections (Etim et al., 2016). The mucus showed anti-bacterial potency against Staphylococcus, Streptococcus, and Pseudomonas isolated from wounds. In the same study, when compared to seven common antibiotics, including amoxicillin, streptomycin, and chloramphenicol, some of the mucus secretions were more inhibitory to infections than commercial antibiotics. Understanding the antimicrobial properties of snail mucus is an active and growing area of research.

\section{Snail Mucins as Drug Delivery Vehicles}

The adaptability of snail mucin biopolymers makes them uniquely promising candidates for novel drug delivery systems (Huckaby and Lai, 2018; Momoh et al., 2020). During mating, male snails shoot a dart to deliver mucus containing accessory proteins into the female, which in turn increases the fertility of the female snail (Lodi et al., 2017). This process relies on a multifunctional system, with each component playing a defined role. The dart acts as a needle, piercing tissue and injecting the mucus that carries the accessory proteins into the 
TABLE 1 | Mollusca species whose mucin have been applied in various sectors for biomedical or biotechnology applications

\begin{tabular}{|c|c|c|c|c|}
\hline Mollusca species & Common name & Applicable sectors & Uses & Development stage \\
\hline Helix aspersa & Garden Snail & Cosmetics & $\begin{array}{l}\text { Skin Care Cancer Treatment Topical } \\
\text { Antibiotic }\end{array}$ & $\begin{array}{l}\text { Commercially available(Benton, Mizon, Cos Rx, } \\
\text { Biopelle, Missha) }\end{array}$ \\
\hline
\end{tabular}
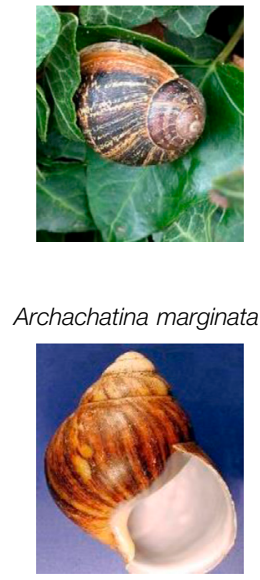

\section{Banana Rasp \\ Antimicrobial Pharmacology}

Snail
Wound Care
Antibiotic Drug Delivery \& Medication

Wound Dressing
Patented for use (US patent \#

WO2000068258A2)

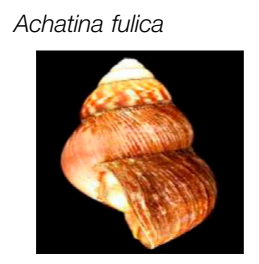

Kalutara snail

Antimicrobial Pharmacology Wound Care
Antibiotic Drug Delivery Medication Wound Dressing
Patented for use (US patent \#: WO2000068258A2)

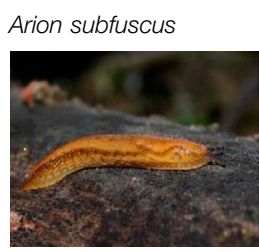

Medical equipment

Surgical glue

Active research (University of Pennsylvania Lehigh University)

Shampoo

Commercially available (Royer)

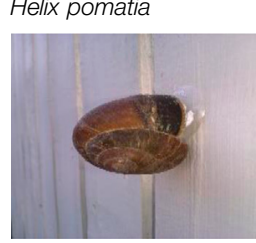

Burgundy snail Personal care

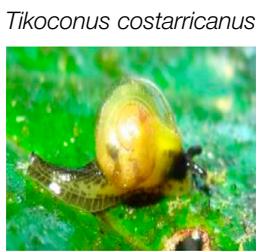

T. costarricanus Biotech

Adhesion and lubrication

Reported in literature

female snail. In a similar manner, mucus could be adapted to act as a delivery vector for bioactive molecules. Snail mucus are known to pair exceptionally well with any medication that is absorbed via mucosal membranes because of their ability to facilitate diffusion across membranes (Balabushevich et al.,
2019). For example, metformin hydrochloride, a diabetes medication, was attached to Giant African Land Snail mucin using polyethylene glycol (PEG) to increase bioavailability of the drug (Momoh et al., 2014). PEGylation, is a commonly utilized process where a therapeutic is surrounded by a matrix of 
TABLE 2 | Molluscan mucin applied as antimicrobials to inhibit pathogens.

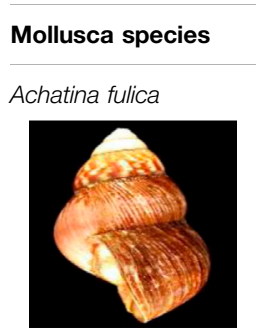

$\begin{array}{ll}\text { Mucin tissue type } & \text { Dose } \\ \text { Foot } & 10 \mathrm{uL} \\ & 10 \mathrm{uL} \\ & 350 \mathrm{Ug} / \mathrm{cm} 3 \\ & 350 \mathrm{Ug} / \mathrm{cm} 3 \\ & 350 \mathrm{Ug} / \mathrm{cm} 3 \\ 4 \mathrm{mg} / \mathrm{ml} \\ 4 \mathrm{mg} / \mathrm{ml} \\ 4 \mathrm{mg} / \mathrm{ml}\end{array}$

\section{Bacteria}

S. aureus

S. epidermidis

B. subtilis

E. coli

$P$. aeruginosa

S. aureus

S. pyogenes

$P$. aeruginosa

Foot

$4.8 \mathrm{mg} / \mathrm{ml}$

P. aeruginosa

Pitt et al. (2015)

References

Mumuni et al. (2020)

Santana et al. (2012)

Etim et al. (2016)
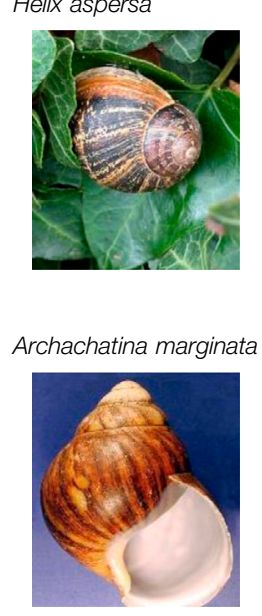

Foot

(
$40 \%$ mucin/water mixture

\author{
S. aureus \\ S. pyogenes \\ $P$. aeruginosa
}

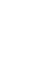


regulation has been linked to cancer progression, the growth of these cell lines was decreased, demonstrating its anti-melanogenic properties (Domínguez-Martín et al., 2020). While still in the early stages of development, the application of snail mucins as anti-tumor agents is of growing interest in the biomedical community.

\section{Snail Mucins Facilitate Wound Healing}

Snail mucus can facilitate healing and has become an important resource in wound research (Michael, 2012; Etim et al., 2016). Mucins from the Helix aspersa (Garden Snail) have been shown to help with skin regeneration after acute radiodermatitis, a common side effect from radiotherapy (Hymes et al., 2006). Garden snail mucus reportedly increased healing rates through antioxidant and free radical regulation (Nguyen et al., 2020). Mucus from garden improved erythema in rat models, and, the same rats showed reduction of photoaging as well (Lim et al., 2020). As well as being able to treat superficial injuries, mucins have shown the ability to be used on internal wounds. Mucins have been incorporated alongside oral non-steroidal antiinflammatory drugs (NSAIDs), to reduce or eliminate gastric mucosal injury (Abdulla et al., 2013). NSAIDs reduce inflammation, but have adverse side effects related to gastrointestinal injury and liver damage. Many companies have turned to natural products to counteract these side effect, and Mucin have been shown to treat peptic ulcers, a side effects caused by NSAIDs (Drina, 2017). A combination of the antibiotic, clarithromycin, and A. fulica mucin has shown positive results in treatment of peptic ulcer disease ( $\mathrm{Mu}$ et al., 2008; Kabakambira et al., 2018). In addition to anti-ulcer properties, the healing rate of ulcers increased with concentration of mucin and was faster than clarithromycin alone.

\section{Snail Mucus Used for Bioinspired Materials}

Studying naturally occurring substances as a platform to build new materials has resulted in multiple revolutionary products, such as Lipitor, Penicillin, and Morphine. Similarly, mucins have been used as a biomaterial coating in order to reduce rejection of inorganic implants. Rejection of surgical implants due to infection results in over 1 million medical cases per year with the cost of the original surgery only being a fraction of the cost of treating the corresponding infection (Darouiche, 2004). Applying mucin-based films to polyethylene terephthalate, a common material used in medical implants, greatly reduced the immune response triggered by $\operatorname{IgG}$ and $\operatorname{IgM}$ absorption into the plastic (Sandberg et al., 2009; Galo Silva et al., 2019). The same study also showed that it reduced the activation of fibrinogen, a known inflammatory agent, when contacting the mucin coating as compared to the uncoated plastic. Mucins have been shown in other studies to reduce microbe reproduction on implanted devices (Co et al., 2015). Mucin-based technologies show immense promise for advancements in the field of biomaterials.

An example of mucins being used as biomaterials is the application of mucins in the synthesis of water-soluble hydrocarbons. By ligating mucin and/or mucin-mimicking compounds with a hydrophobic lipid chain, the hydrocarbon complex remained suspended in aqueous conditions, even after several months, while the non-complexed hydrocarbon would precipitate rapidly from solution (Chen et al., 2004). In another related study conducted by Combaa's group, this property was applied to enhance glucose detection by creating a stabilized suspension of carbon nanotube-mucin complex for a sandwichtype glucose biosensor. The resulting bioanalytical device is $20 \%$ more sensitive and $40 \%$ faster than conventional devices that do not include this sensor design matrix (Comba et al., 2018).

Mucins, which come into contact with medications absorbed through mucosal membranes, can also be used in chromatography to assist in determining bioavailability and absorption through the membrane (Gargano et al., 2014). Porcine gastric mucin, bound to the silica column via amino propyl linkers, allowed for separation of drug molecules by the drug's mucus membrane binding affinity. In another study mucin was anchored to a column using an ion-exchange with calciumalginate, the mucin is immobilized, mimicking biological mucus membranes. Longer retention time of the molecule within the mucin column indicated high drug-mucin interaction, which is correlated to delayed bioavailability in vivo (Bhat, 1995). This adds another dimension to evaluate medications used in specific diseases that affect mucin production, such as cystic fibrosis (Abdullah et al., 2018).

The same porcine gastric mucin column has been used to evaluate flavor retention by the food industry. The mucin column was shown to mimic a bovine tongue for flavor retention, which reduces the need for and could potentially eliminate animal testing (Dinu et al., 2019). Mucins have been extensively studied in their role with flavor perception (Çelebioğlu et al., 2020). The presence of mucins within the oral cavity has been directly correlated to increased sedimentation of flavorproducing compounds, which in turn increases flavor perception (Dinu et al., 2020). This phenomenon is also being examinned as the cause for the loss of taste in old age (Pushpass et al., 2019a). Decreased levels of MUC7 in saliva has been noted in older individuals decreased taste (Pushpass et al., 2019b). This downregulation is believed to reduce mucoadhesion of the flavor molecules, leading to attenuated taste perception.

\section{A Snail's Pace to Characterization of Mucin Molecules}

Despite growing interest in the field, there are still many obstacles that prevent advancements in snail mucin research. Many snail species that have the potential for novel mucin discovery are often inaccessible because of their habitat. The lack of readily accessible biological material samples and difficulty in identifying mucin structures prevents the reliable synthesis of mucins in quantities sufficient for repeated experimentation. Several groups are investigating sustainable, scalable approaches to producing synthetic mucins, however the field is in its infancy (Petrou and Crouzier, 2018) While mucins that have been isolated from the A. fulica have been extensively studied, other species remain neglected (Park, 2011).

The most viable method for commercial mucin production remains extraction and isolation from animals, which does not allow for substantial yields for application without abundant 
animal capital and generally involves invasive methods. The complexity, abundance, and localization of glycosylation patterns on each mucin, in addition to various mucin glycoforms cause difficulty in employing common separation methods to purify, synthesize, and analyze mucin samples (Navarro et al., 2018). Mucins often undergo posttranslational modifications, such as O-sulfation, $\mathrm{N}$-sulfation, and $\mathrm{N}$-deacetylation that differentiate function between proteins (Krasnova and Wong, 2016). These posttranslational glycan modifications are a hurdle to mucin sample purification, characterization, and synthesis. A promising synthetic approach involves using recombinant bacteria, glycosyltransferase(GT)-mediated polymerization, and trans-glycosylation (Krasnova and Wong, 2016). However, these methods are insufficient to achieve industrially practical yields and will fail to generate the exhaustive set of glycoforms that comprise natural mucus gels. There is still difficulty in creating the O-glycosylation in yeast, and there are challenges involved in transferring glycosylation branches to chosen protein residues. These issues present a need for developing viable and high yield methods for synthesizing mucins using scalable chemistries, which would be the first step in using mucins as targeted therapies or treatments (Kwan et al., 2020).

Recent years have seen the emergence of -omic technologies (genomics, transcriptomics, proteomics, glycomics) that require minimal amounts of samples, allowing for the characterization of rare or poorly accessible snail samples (Gorson et al., 2015). A similar strategy to what has been done with snail venoms using venomics (Holford et al., 2018; Anand et al., 2019; Fassio et al., 2019), which pairs transcriptomic and proteomic methods with de novo sequence bioinformatic assembly programs to identify the genetic structure of snail venom putative peptide toxins, can be applied to characterize mucin genes and mucus proteins (Figure 1). Specifically, by taking the nucleotide sequences of assembled exomes, and then pairing that with proteomic mass values, we can confirm linear mucin protein structures. In this approach we extract mRNA from mucus glands or whole animal and through a bioinformatic pipeline, identify mucin genes and primary mucin protein sequences. A new initiative, the Comparative Animal Mucomics Project (CAMP) will apply a systematic comparative analyses of mucin genes and mucus hydrogels to determine the hierarchical structures and properties of distinct mucuses (Cerullo, 2020).

Despite the promise of omic methods for producing robust databases of mucins, major hurdles still remain for their study. One such hurdle are the algorithms used to assemble sequenced genes. De Bruijn graphs, which is the algorithm sequence most assemblers use, have difficulty mapping the repeated domains due to the multiplicity of similar overlapped sequences (Mikheenko et al., 2020). Multiple tools are currently being developed to overcome this problem (Jain et al., 2020). Each program changes the weighting of the k-mers that are used to construct the De Bruijn graphs in order to accommodate for the tandem repeats. For mucin proteomic study, the intermolecular interactions of mucins with other mucins causes an additional degree of difficulty.
Mucins naturally will create multimers of themselves, connecting multiple proteins together in order to form a larger structure, which is regularly observed in nature (Javitt et al., 2019). In order to then obtain a single protein, the cojoined bonds must be broken, without also breaking the bonds of the single protein. However, mucin multimer bonds are difficult to reduce without also having an effect on the rest of a single mucin chain's secondary structure. A trial and error procedure is currently used in mucin proteomic studies to generate single protein masses. New characterization and synthesis techniques will need to be established to accurately identify and fabricate snail mucins, and with an omics approach we may be able to determine the genotype to phenotype mapping necessary to understand and decipher the functionality differences found in each mucin sample.

\section{CONCLUDING REMARKS AND FUTURE PERSPECTIVES}

Snails are found in nearly every biome, and environmental conditions appear to drive the diversity of mucin genes and versatility of mucus functions (Lang et al., 2007; Lang et al., 2016). Snail mucins have demonstrated biomedical and biotechnology potential, and are a bioinspired resource of significant promise (Figure 1). Characterization of snail mucins are limited not by their inherent value, but by access and the complexity of the molecule's identification, purification and investigation. There are still several questions left to be answered about the properties of mucins and mucuses in relation to the applicable uses. This prospective demonstrates the high yield potential of snail mucins, and by utilizing an adaptable comparative omics pipeline, we can better understand these unique proteins, and their advantageous biological and chemical properties.

\section{AUTHOR CONTRIBUTIONS}

$\mathrm{MH}$ and MM conceived of the review. $\mathrm{AB}, \mathrm{AC}$, JP contributed to content. MM wrote the first draft of the manuscript. EA, WD, SS, SS, and JF wrote sections of the manuscript. All authors contributed to manuscript revision, read, and approved the submitted version.

\section{FUNDING}

$\mathrm{MH}$ acknowledges support from the National Institutes of Health (NIH-NIMHD grant 8-G- 12-MD007599). Student support for SS provided by Hunter Yalow Scholars program, JF was provided by the Hunter College NIH-MARC program, Grant \#GM007823, and SS was provided by the Hunter McNulty Program. AC acknowledges support from the CUNY Graduate Center Graduate Fellowship program and a CUNY Llewellyn Fellowship. AB acknowledges support from the Air Force Office of Scientific Research Grant Number (FA9550-19-1-0220). 


\section{REFERENCES}

Abdulla, A., Adams, N., Bone, M., Elliott, A. M., Gaffin, J., Jones, D., et al. (2013). Guidance on the Management of Pain in Older People. Age Ageing 42, i1-i57. doi:10.1093/ageing/afs200

Abdullah, L. H., Coakley, R., Webster, M. J., Zhu, Y., Tarran, R., Radicioni, G., et al. (2018). Mucin Production and Hydration Responses to Mucopurulent Materials in Normal versus Cystic Fibrosis Airway Epithelia. Am. J. Respir. Crit. Care Med. 197, 481-491. doi:10.1164/rccm.201706-1139oc

Agu, M. O., Tsware, B. J., Sunday, A. O., Onwuka, J. C., and Anthony, H. J. (2018). Investigatory Study of Long Term Doses of Costus Afer, Snail Slime, and Their Combination with a Standard Pharmaceutical Drug on Blood Glucose Level of Alloxan Induced Swiss Albino Rat. Open J. Med. Chem. 08, 1-14. doi:10.4236/ ojmc. 2018.81001

Amah, A. K., Ewa, O., Karimah, M. R., Elendu, M. U., and Yunusa, Z. (2019). Effect of Archachatina Marginata Mucin on the Aggressive Factors of Gastric Ulcer Challenged Wistar Rat Stomach Tissue. GSC Biol. Pharm. Sci. 9, 077-082. doi:10.30574/gscbps.2019.9.1.0163

Anand, P., Filipenko, P., Huaman, J., Lyudmer, M., Hossain, M., Santamaria, C., et al. (2019). Selective Inhibition of Liver Cancer Cells Using Venom Peptide. Mar. Drugs 17 (10), 587. doi:10.3390/md17100587

Balabushevich, N. G., Kovalenko, E. A., Le-Deygen, I. M., Filatova, L. Y., Volodkin, D., and Vikulina, A. S. (2019). Hybrid CaCO3-Mucin Crystals: Effective Approach for Loading and Controlled Release of Cationic Drugs. Mater. Des. 182, 108020. doi:10.1016/j.matdes.2019.108020

Balabushevich, N., Sholina, E., Mikhalchik, E., Filatova, L., Vikulina, A., and Volodkin, D. (2018). Self-Assembled Mucin-Containing Microcarriers via Hard Templating on CaCO3 Crystals. Micromachines 9, 307. doi:10.3390/ mi9060307

Bansil, R., and Turner, B. S. (2006). Mucin Structure, Aggregation, Physiological Functions and Biomedical Applications. Curr. Opin. Colloid Interf. Sci. 11, 164-170. doi:10.1016/j.cocis.2005.11.001

Barrientos, Z. (2020). A New Aestivation Strategy for Land Molluscs: Hanging Upside Down like Bats. UNED Res. J. 12, e2802. doi:10.22458/urj.v12i1.2802

Benktander, J., Venkatakrishnan, V., Padra, J. T., Sundh, H., Sundell, K., Murugan, A. M., et al. (2019). Effects of Size and Geographical Origin on Atlantic salmon, Salmo salar, Mucin O-Glycan Repertoire. Mol. Cell Proteomics 18, 1183-1196. doi:10.1074/mcp.ra119.001319

Bhat, P. (1995). The Limiting Role of Mucus in Drug Absorption: Drug Permeation through Mucus Solution. Int. J. Pharmaceutics 126, 179-187. doi:10.1016/03785173(95)04120-6

Bornhöfft, K. F., Goldammer, T., Rebl, A., and Galuska, S. P. (2018). Siglecs: A Journey through the Evolution of Sialic Acid-Binding Immunoglobulin-type Lectins. Develop. Comp. Immunol. 86, 219-231. doi:10.1016/j.dci.2018.05.008

Brockhausen, I. (1999). Pathways of O-Glycan Biosynthesis in Cancer Cells. Biochim. Biophys. Acta 1473, 67-95. doi:10.1016/s0304-4165(99)00170-1

Çelebioğlu, H. Y., Lee, S., and Chronakis, I. S. (2020). Interactions of Salivary Mucins and Saliva with Food Proteins: a Review. Crit. Rev. Food Sci. Nutr. 60, 64-83. doi:10.1080/10408398.2018.1512950

Cerullo, A. R. (2020). Comparative Animal Mucomics: Inspiration for Functional Materials from Ubiquitous and Understudied Biopolymers. ACS Biomater. Sci. Eng., 6, 5377-5398. doi:10.1021/acsbiomaterials.0c00713

Chen, X., Lee, G. S., Zettl, A., and Bertozzi, C. R. (2004). Biomimetic Engineering of Carbon Nanotubes by Using Cell Surface Mucin Mimics. Angew. Chem. Int. Ed. 43, 6111-6116. doi:10.1002/anie.200460620

Co, J. Y., Crouzier, T., and Ribbeck, K. (2015). Probing the Role of Mucin-Bound Glycans in Bacterial Repulsion by Mucin Coatings. Adv. Mater. Inter. 2, 1500179. doi:10.1002/admi.201500179

Coherent Market Inisghts (2018). Global Snail Beauty Products Market Analysis. Mar 23, 2018. [Online]. Available at: https://www.coherentmarketinsights.com/ press-release/global-snail-beauty-products-market-to-surpass-us-7695million-by-2025-754 (Accessed 04 Feb, 2021).

Comba, F. N., Romero, M. R., Garay, F. S., and Baruzzi, A. M. (2018). Mucin and Carbon Nanotube-Based Biosensor for Detection of Glucose in Human Plasma. Anal. Biochem. 550, 34-40. doi:10.1016/j.ab.2018.04.006

Corfield, A. P. (2015). Mucins: A Biologically Relevant Glycan Barrier in Mucosal protection. Biochim. Biophys. Acta 1850, 236-252. doi:10.1016/j.bbagen.2014.05.003
Darouiche, R. O. (2004). Treatment of Infections Associated with Surgical Implants. N. Engl. J. Med. 350, 1422-1429. doi:10.1056/nejmra035415

Dhanisha, S. S., Guruvayoorappan, C., Drishya, S., and Abeesh, P. (2018). Mucins: Structural Diversity, Biosynthesis, its Role in Pathogenesis and as Possible Therapeutic Targets. Crit. Rev. Oncology/Hematology 122, 98-122. doi:10.1016/ j.critrevonc.2017.12.006

Dinu, V., MacCalman, T., Yang, N., Adams, G. G., Yakubov, G. E., Harding, S. E., et al. (2020). Probing the Effect of Aroma Compounds on the Hydrodynamic Properties of Mucin Glycoproteins. Eur. Biophys. J. 49, 799-808. doi:10.1007/ s00249-020-01475-4

Dinu, V., Yakubov, G. E., Lim, M., Hurst, K., Adams, G. G., Harding, S. E., et al. (2019). Mucin Immobilization in Calcium Alginate: A Possible Mucus Mimetic Tool for Evaluating Mucoadhesion and Retention of Flavour. Int. J. Biol. Macromolecules 138, 831-836. doi:10.1016/j.ijbiomac.2019.07.148

Domínguez-Martín, E. M., Tavares, J., Ríjo, P., and Díaz-Lanza, A. M. (2020). Zoopharmacology: A Way to Discover New Cancer Treatments. Biomolecules 10, 1-20. doi:10.3390/biom 10060817

Drina, M. (2017). Peptic Ulcer Disease and Non-steroidal Anti-inflammatory Drugs. Aust. Prescr. 40, 91-93. doi:10.18773/austprescr.2017.037

Dutta, D., Sailapu, S. K., Simon, A. T., Ghosh, S. S., and Chattopadhyay, A. (2019). Gold-Nanocluster-Embedded Mucin Nanoparticles for Photodynamic Therapy and Bioimaging. Langmuir 35, 10475-10483. doi:10.1021/ acs.langmuir.9b00998

Ekin, İ. (2018). Molluscs: Their Usage as Nutrition, Medicine, Aphrodisiac, Cosmetic, Jewelry, Cowry, Pearl, Accessory and So on from the History to Today. mejs 4, 45-51. doi:10.23884/mejs.2018.4.1.06

Ellijimi, C., Ben Hammouda, M., Othman, H., Moslah, W., Jebali, J., Mabrouk, H. B., et al. (2018). Helix Aspersa Maxima Mucus Exhibits Antimelanogenic and Antitumoral Effects against Melanoma Cells. Biomed. Pharmacother. 101, 871-880. doi:10.1016/j.biopha.2018.03.020

Etim, L., Aleruchi, C., and Obande, G. (2016). Antibacterial Properties of Snail Mucus on Bacteria Isolated from Patients with Wound Infection. British Microbiology Research Journal 11, 1-9. doi:10.9734/bmrj/2016/ 21731

Fassio, G., Modica, M. V., Mary, L., Zaharias, P., Fedosov, A. E., Gorson, J, et al (2019). Venom Diversity and Evolution in the Most Divergent Cone Snail Genus Profundiconus. Toxins (Basel) 11 (11), 623. doi:10.3390/toxins11110623

Galo Silva, G., Valente, M. L. D. C., Bachmann, L., and dos Reis, A. C. (2019). Use of Polyethylene Terephthalate as a Prosthetic Component in the Prosthesis on an Overdenture Implant. Mater. Sci. Eng. C 99, 1341-1349. doi:10.1016/ j.msec.2019.01.136

Gargano, A. F. G., Lämmerhofer, M., Lönn, H., Schoenmakers, P. J., and Leek, T. (2014). Mucin-based Stationary Phases as Tool for the Characterization of Drug-Mucus Interaction. J. Chromatogr. A 1351, 70-81. doi:10.1016/ j.chroma.2014.05.031

Gentili, V., Bortolotti, D., Benedusi, M., Alogna, A., Fantinati, A., Guiotto, A., et al. (2020). HelixComplex Snail Mucus as a Potential Technology against O3 Induced Skin Damage. PLoS One 15, e0229613. doi:10.1371/ journal.pone.0229613

Gerdol, M. (2017). Immune-related Genes in Gastropods and Bivalves: A Comparative Overview. Invertebr. Surviv. J. 14, 103-118.

Gorson, J., Ramrattan, G., Verdes, A., Wright, E. M., Kantor, Y., Rajaram Srinivasan, R., et al. (2015). Molecular Diversity and Gene Evolution of the Venom Arsenal of Terebridae Predatory Marine Snails. Genome Biol. Evol. 7, 1761-1778. doi:10.1093/gbe/evv104

Gould, J., Valdez, J. W., and Upton, R. (2019). Adhesive Defence Mucus Secretions in the Red triangle Slug ( Triboniophorus Graeffei ) Can Incapacitate Adult Frogs. Ethology 125, 587-591. doi:10.1111/eth.12875

Gugu, T. H., Onwusoba, R. C., Onyi, P. N., and Ozioko, A. C. (2020). Synergistic Interaction of Natural Snail Mucin and Lincomycin for ImmunoChemotherapy against Streptopneumococcal Infection: Checkerboard Evaluations. Int. J. Pharm. Invest. 10, 379-383. doi:10.5530/ijpi.2020.3.67

Guillen-Poza, P. A., Sánchez-Fernández, E. M., Artigas, G., García Fernández, J. M., Hinou, H., Ortiz Mellet, C., et al. (2020). Amplified Detection of Breast Cancer Autoantibodies Using MUC1-Based Tn Antigen Mimics. J. Med. Chem. 63, 8524-8533. doi:10.1021/acs.jmedchem.0c00908

Holford, M., Daly, M., King, G. F., and Norton, R. S. (2018). Venoms to the rescue. Science 361, 842-844. doi:10.1126/science.aau7761 
Huckaby, J. T., and Lai, S. K. (2018). PEGylation for Enhancing Nanoparticle Diffusion in Mucus. Adv. Drug Deliv. Rev. 124, 125-139. doi:10.1016/j.addr.2017.08.010

Hymes, S. R., Strom, E. A., and Fife, C. (2006). Radiation Dermatitis: Clinical Presentation, Pathophysiology, and Treatment 2006. J. Am. Acad. Dermatol. 54, 28-46. doi:10.1016/j.jaad.2005.08.054

Iguchi, S. M. M., Aikawa, T., and Matsumoto, J. J. (1982). Antibacterial Activity of Snail Mucus Mucin. Comp. Biochem. Physiol. A: Physiol. 72, 571-574. doi:10.1016/0300-9629(82)90123-2

Jain, C., Rhie, A., Zhang, H., Chu, C., Walenz, B. P., Koren, S., et al. (2020). Weighted Minimizer Sampling Improves Long Read Mapping. Bioinformatics 36, i111-i118. doi:10.1093/bioinformatics/btaa435

Javitt, G., Calvo, M. L. G., Albert, L., Reznik, N., Ilani, T., Diskin, R., et al. (2019). Intestinal Gel-Forming Mucins Polymerize by Disulfide-Mediated Dimerization of D3 Domains. J. Mol. Biol. 431, 3740-3752. doi:10.1016/j.jmb.2019.07.018

Kabakambira, J. D., Hategeka, C., Page, C., Ntirenganya, C., Dusabejambo, V., Ndoli, J., et al. (2018). Efficacy of Helicobacter pylori Eradication Regimens in Rwanda: A Randomized Controlled Trial. BMC Gastroenterol. 18, 134. doi:10.1186/s12876-018-0863-2

Krasnova, L., and Wong, C.-H. (2016). Understanding the Chemistry and Biology of Glycosylation with Glycan Synthesis. Annu. Rev. Biochem. 85, 599-630. doi:10.1146/annurev-biochem-060614-034420

Kwan, C. S., Cerullo, A. R., and Braunschweig, A. B. (2020). Design and Synthesis of Mucin-Inspired Glycopolymers. Chempluschem 85, 2704-2721. doi:10.1002/ cplu.202000637

Lang, T., Hansson, G. C., and Samuelsson, T. (2007). Gel-forming Mucins Appeared Early in Metazoan Evolution. Proc. Natl. Acad. Sci. 104, 16209-16214. doi:10.1073/pnas.0705984104

Lang, T., Klasson, S., Larsson, E., Johansson, M. E. V., Hansson, G. C., and Samuelsson, T. (2016). Searching the Evolutionary Origin of Epithelial Mucus Protein Components-Mucins and FCGBP. Mol. Biol. Evol. 33, 1921-1936. doi:10.1093/molbev/msw066

Lim, V. Z., Yong, A. A., Tan, W. P. M., Zhao, X., Vitale, M., and Goh, C. L. (2020). Efficacy and Safety of a New Cosmeceutical Regimen Based on the Combination of Snail Secretion Filtrate and Snail Egg Extract to Improve Signs of Skin Aging. J. Clin. Aesthet. Dermatol. 13, 31-36.

Linden, S. K., Sutton, P., Karlsson, N. G., Korolik, V., and McGuckin, M. A. (2008). Mucins in the Mucosal Barrier to Infection. Mucosal Immunol. 1, 183-197. doi:10.1038/mi.2008.5

Lodi, M., Staikou, A., Janssen, R., and Koene, J. M. (2017). High Level of Sperm Competition May Increase Transfer of Accessory Gland Products Carried by the Love Dart of Land Snails. Ecol. Evol. 7, 11148-11156. doi:10.1002/ece3.3385

Ma, J., Rubin, B. K., and Voynow, J. A. (2018). Mucins, Mucus, and Goblet Cells. Chest 154, 169-176. doi:10.1016/j.chest.2017.11.008

Martins, M. D. F., Caetano, F. A. M., Sírio, O. J., Yiomasa, M. M., Mizusaki, C. I., and Figueiredo, L. D. (2003). Avaliação macro e microscópica da cicatrização de lesões experimentalmente provocadas em pele de coelhos tratadas com secreção mucoglicoproteica Do escargot Achatina fulica. Braz. J. Vet. Res. Anim. Sci. 40, 213. doi:10.1590/s1413-95962003000900009

A. Michael (Editor) (2012). "Multifarious Potentials of Tropical Animal-Derived Biopolymers in Drug Delivery: Lessons from the African Snail Mucin," Biopolymers in Drug Delivery: Recent Advances and Challenges (Sharjah, UAE: BENTHAM SCIENCE PUBLISHERS), 27-38. doi:10.2174/ 978160805078910901010027

Mikheenko, A., Bzikadze, A. V., Gurevich, A., Miga, K. H., and Pevzner, P. A. (2020). TandemTools: Mapping Long Reads and Assessing/improving Assembly Quality in Extra-long Tandem Repeats. Mar. Drugs 17, i75-i83. doi:10.1093/bioinformatics/btaa440

Momoh, M. A., Akpa, P. A., Ugwu, K. C., Kenechukwu, F. C., and Kenneth, O. C. (2020). Pharmacodynamics and Pharmacokinetics Behaviour of Insulin from PEGylated-Mucin Microparticles Coated with $\mathrm{pH}$ Sensitive Polymer: Preparation and Characterization. Mater. Today Commun. 25, 101539. doi:10.1016/j.mtcomm.2020.101539

Momoh, M., Adedokun, M., Adikwu, M., and Ibezim, C. (2014). In Vitro evaluation of PEGylated-Mucin Matrix as Carrier for Oral Delivery of Metformin Hydrochloride. Trop. J. Pharm. Res. 13, 1039-1045. doi:10.4314/tjpr.v13i7.5

Mu, A., Okolie, C. O., and Agboke, A. (2008). The Effect of Snail Mucin on the Ulcer Healing Rate of Clarithromycin. J. Pharm. Res. 8, 6. doi:10.18579/jpcrkc/ 2009/8/1/79523
Mumuni, M. A., Kenechukwu, F. C., Ofokansi, K. C., Attama, A. A., and Díaz, D. D. (2020). Insulin-loaded Mucoadhesive Nanoparticles Based on Mucin-Chitosan Complexes for Oral Delivery and Diabetes Treatment. Carbohydr. Polym. 229, 115506. doi:10.1016/j.carbpol.2019.115506

Navarro, L. A., French, D. L., and Zauscher, S. (2018). Advances in Mucin Mimic Synthesis and Applications in Surface Science. Curr. Opin. Colloid Interf. Sci. 38, 122-134. doi:10.1016/j.cocis.2018.09.004

Nguyen, J. K., Masub, N., and Jagdeo, J. (2020). Bioactive Ingredients in Korean Cosmeceuticals: Trends and Research Evidence. J. Cosmet. Dermatol. 19, 1555-1569. doi:10.1111/jocd.13344

Park, Y. (2011). Mining Invertebrate Natural Products for Future Therapeutic Treasure. Nat. Prod. Commun. 6 (9), 1403-1408. doi:10.1177/1934578x1100600944

Perez-Vilar, J., and Hill, R. L. (1999). The Structure and Assembly of Secreted Mucins. J. Biol. Chem. 274, 31751-31754. doi:10.1074/jbc.274.45.31751

Petrou, G., and Crouzier, T. (2018). Mucins as Multifunctional Building Blocks of Biomaterials. Biomater. Sci. 6, 2282-2297. doi:10.1039/c8bm00471d

Pitt, S. J., Graham, M. A., Dedi, C. G., Taylor-Harris, P. M., and Gunn, A. (2015). Antimicrobial Properties of Mucus from the Brown Garden Snail Helix Aspersa. Br. J. Biomed. Sci. 72, 174-181. doi:10.1080/09674845.2015.11665749

Premi, S. (2020). Role of Melanin Chemiexcitation in Melanoma Progression and Drug Resistance. Front. Oncol. 10. doi:10.3389/fonc.2020.01305

Pushpass, R.-A. G., Pellicciotta, N., Kelly, C., Proctor, G., and Carpenter, G. H. (2019). Reduced Salivary Mucin Binding and Glycosylation in Older Adults Influences Taste in an In Vitro Cell Model. Nutrients 11, 2280. doi:10.3390/ nu11102280

Pushpass, R. G., Daly, B., Kelly, C., Proctor, G., and Carpenter, G. H. (2019). Altered Salivary Flow, Protein Composition, and Rheology Following Taste and TRP Stimulation in Older Adults. Front. Physiol. 10, 652. doi:10.3389/fphys.2019.00652

Rose, M. C., and Voynow, J. A. (2006). Respiratory Tract Mucin Genes and Mucin Glycoproteins in Health and Disease. Physiol. Rev. 86, 245-278. doi:10.1152/ physrev.00010.2005

Rutkowski, P., and Kozak, K. (2017). News from the Melanoma Sessions of the European Cancer Congress 2017. BMC Med. 15, 57. doi:10.1186/s12916-0170826-4

Sandberg, T., Karlsson Ott, M., Carlsson, J., Feiler, A., and Caldwell, K. D. (2009). Potential Use of Mucins as Biomaterial Coatings. II. Mucin Coatings Affect the Conformation and Neutrophil-Activating Properties of Adsorbed Host Proteins-Toward a Mucosal Mimic. J. Biomed. Mater. Res. 91A, 773-785. doi:10.1002/jbm.a.32315

Santana, W. A., Melo, C. M. d., Cardoso, J. C., Pereira-Filho, R. N., Rabelo, A. S., Reis, F. P., et al. (2012). Assessment of Antimicrobial Activity and Healing Potential of Mucous Secretion of Achatina fulica. Int. J. Morphol. 30, 365-373. doi:10.4067/s0717-95022012000200001

Sompayrac, L. M. (2012). How the Immune System Works. 4th Editio.

Van Putten, J. P. M., and Strijbis, K. (2017). Transmembrane Mucins: Signaling Receptors at the Intersection of Inflammation and Cancer. J. Innate Immun. 9, 281-299. doi:10.1159/000453594

Yan, H., Hjorth, M., Winkeljann, B., Dobryden, I., Lieleg, O., and Crouzier, T. (2020). Glyco-Modification of Mucin Hydrogels to Investigate Their Immune Activity. ACS Appl. Mater. Inter. 12, 19324-19336. doi:10.1021/acsami.0c03645

Conflict of Interest: The authors declare that the research was conducted in the absence of any commercial or financial relationships that could be construed as a potential conflict of interest.

Publisher's Note: All claims expressed in this article are solely those of the authors and do not necessarily represent those of their affiliated organizations, or those of the publisher, the editors and the reviewers. Any product that may be evaluated in this article, or claim that may be made by its manufacturer, is not guaranteed or endorsed by the publisher.

Copyright $\odot 2021$ McDermott, Cerullo, Parziale, Achrak, Sultana, Ferd, Samad, Deng, Braunschweig and Holford. This is an open-access article distributed under the terms of the Creative Commons Attribution License (CC BY). The use, distribution or reproduction in other forums is permitted, provided the original author(s) and the copyright owner(s) are credited and that the original publication in this journal is cited, in accordance with accepted academic practice. No use, distribution or reproduction is permitted which does not comply with these terms. 